\title{
COMUNICAÇÃO CIFNTIFICA
}

\section{ADENDO A LISTAGEM DE INSETOS, ÁCAROS E NEMATOIDES DE IMPORTÂNCIA QUARENTENARIA PARA A VIDEIRA NO BRASIL 1}

\author{
Saulo de J. Sória ${ }^{2}$ \\ Gilmar B. Kuhn ${ }^{2}$
}

RESUMO

o objetivo é o de apresentar uma lista de insetos, ácaros e nematóides de provável importância quarentenária para a viticultura do Brasil e que complemente a já existente, elabo rada pelo Ministério da Agricultura. Na elaboração da listagem, faz-se a separação em dois grupos de organismos: no primeiro, estão aqueles de importância quarentenária doméstica, isto é, aqueles que, sendo introduzidos ou endêmicos, têm dis tribuição restrita dentro de alguns municípios ou Estados dā Federação. Sugere-se medidas de proteção fitossanitária regulamentar para impedir a sua entrada em áreas ainda isentas do problema. o método de estabelecimento de cinturão fitossanitá rio tem mostrado eficácia na prevenção de danos em alguns cul tivos do país.

o segundo grupo è constituído por organismos de importân cia quarentenāria internacional que, por terem ocasionado com provados danos econômicos de expressiva significância nos paí ses onde ocorrem, devem ser observados cuidadosamente nas rot $\bar{i}$ nas portuárias de inspeção fitossanitária, visando impedir $\bar{a}$ sua entrada no âmbito da Federação.

Menciona-se, a seguir, os nomes dos organismos dentro dos respectivos grupos. São feitas anotações sobre a natureza do seu dano, biologia, hábitos e possivel maneira de introdução, para auxiliar, assim, os inspetores portuários na inspeção fi tossanitária. Sugere-se métodos de destruição apōs sua deteç̧ão.

1 Recebido em 23/04/86.

2

EMBRAPA/Centro Nacional de Pesquisa de Uva e Vinho (CNPUV), Caixa Postal 130, 95700 Bento Gonçalves, RS. 


\section{INSETOS DE IMPORTÃNCIA QUARENTENARIA DOMESTICA}

Eurhizococcus brasiziensis (Hempel, 1922) (Homoptera, Mar garodidae).

O Ministério da Agricultura, considerando que a praga an tes adscrita no Rio Grande do Sul foi assinalada nos Estados do Paraná e Santa Catarina, resolveu, através da Portaria no 28, de 25 de janeiro de 1972, publicada no Diário oficial de 28 de janeiro de 1972, estender a obrigatoriedade da emissão de permissão de trânsito para mudas, bacelos e galhos de plan tas frutiferas, procedentes dos Estados de Santa Catarina e Paraná, nos termos do artigo 29 do Regulamento de Defesa Sani tária Vegetal aprovado pelo Decreto no 24.114 de 12 de abrī de 1934 (Brasil, Ministério da Agricultura, 1979, 1980, 1983).

Este inseto, registrado no Brasil há muitos anos (WILLE, 1922, 1924 e SILVA et al., 1967, 1968), vem causando danos se veros à videira e a aproximadamente 70 outras plantas cultivā das e silvestres, sendo considerado de importância quarentenă ria doméstica porque a sua distribuição está restrita ao sū do pais (PANIZZI \& NOAL, 1971). Dadas as suas caracteristicas biológicas de latência, como pérola misturada na terra, e ao seu amplo politrofismo, atacando plantas botanicamente diversas, o inseto pode ser facilmente conduzido de um lugar para o outro misturado com a terra, ou na forma de ovos ou larvas primárias junto de plantas ornamentais ou em plantas de inte resse econômico, em caqueiros ou mudas com terriço. (GALLOTTI, 1976). Métodos tradicionais de controle químico têm fracassado no combate deste inseto (GALLO et al., 1978). Assim, neste caso, o controle preventivo é justificado através da fiscalização fitossanitária (cinturão fitossanitário) ou através de campanhas de conscientização do grande publico, alertando-o quanto ao perigo de sua condução de um lugar para o outro.

Margarodes vitium (Giard, 1894) (Homoptera, Margarodidae), cochonilha do Chile, peróla da terra, margarodes da videira.

A presença de Margarodes vitium foi assinalada em 1915 no municipio de Uruguaiana, RS, conforme GOBBATO (1940), para sitando videiras.

Esta espécie polífaga tem sua distribuição principal registrada no Chile e Argentina (GONZALES et al., 1969 e MARINLEON, 1968). A praga, assim, tem se mantido restrita ao extre mo sul do Continente, sendo consequentemente considerada pragā de importância quarentenária doméstica para os Estados ao nor te do Rio Grande do Sul.

o controle químico, de acordo com GONZALES et al. (1969), pode ser feito com alguns inseticidas sistêmicos, sem comprọ vação de economicidade. O tráfego de mudas do sul para o nor- 
te do país deve receber fiscalização fitossanitária. Por outro lado, campanhas de conscientização popular quanto ao peri go da disseminação da praga para outras regiões agrícolas devem complementar a ação de fiscalização fitossanitária.

Daetyrosphaera vitifoliae (Schimer, 1867) (Homoptera, Phyl loxeridae), filoxera da videira.

E um inseto que, tendo recebido atenção da pesquisa, par ticularmente nos países europeus, e por se contar com métodos de controle relativamente eficazes através do uso de porta-en xertos americanos tolerantes à forma radicular da filoxera, continua ainda a causar danos, em condições brasileiras, à par te áerea e principalmente em porta-enxertos destinados à produção de sarmento, pela diminuição de sua capacidade fotossin tētica. O inseto está principalmente distribuído no sul dō país, onde a videira é mormente cultivada (SILVA et al., 1967); GALLO et $\alpha$ l., 1978). Existe perigo de se levar a praga para o nordeste na região do Rio são Francisco, onde se prevê viticultura dedicada à produção de uva de mesa.

\section{INSETOS, ĀCAROS E NEMATOIDES DE IMPORTÃNCIA QUARENTENARIA INTERNACIONAL}

\section{Empoasca flavescens e Scaphoides littoralis (Homoptera, Cicadelidae), cigarrinhas da videira.}

Ambos os insetos do hemisfério norte são de provável importância quarentenária para o Brasil. A preocupação com rela ção aos mesmos está relacionada a sua importância como pragás em seus países de origem (Europa e Estados Unidos). O primeiro, E. flavescens "queima" as folhas destruindo a sua capacidade fotossintetizante. O segundo $S$. littoralis transmite o agente causal da doença denominada "Amarelamento micoplásmico" ("Flavescence dorée") de difícil controle e ocorrente, princi palmente, no sudoeste da França (CAUDWELL et al.,1978, 1981; GALET, 1982; MOUTOUS \& FOS, 1972, 1973; e MOUTOUS et a $2 ., 1977$ ). A fiscalização fitossanitāria internacional deve estax particularmente atenta ao exame de material vivo proveniente da França e de outros países europeus, de onde os insetos podem ser introduzidos na forma de ovos e/ou ninfas.

A probabilidade de introdução destes insetos na forma adulta é pequena, visto que o adulto é voador ativo, pouco preso ao hospedeiro. Mesmo assim, o risco de introdução sob formas imaturas persiste e justifica as medidas de precaução. Após verificada a sua presença, o controle pode ser feito por meio de fumigação com brometo de metila ou com inseticidas fos forados, tais como o parathion metilico, via pulverização a $\bar{l}$ to volume. 
Lobesia botrana Den et Schiff (Lepidoptera, Tortricidae), Eudêmia ou traça dos cachos.

Este inseto provém do hemisfério norte, sendo de provável importância quarentenária para a viticultura do Brasil. É uma espécie multivoltina que alcança até quatro gerações por ano (GALET, 1982). De acordo com GALET (1982), ROECHRIK \& SCHMID (1979) e ROECHRIK (1981), o número de gemas destruídas por uma única larva varia entre 7 e 34 e frequlemente as lagar tinhas se encontram em número de 4 a 6 num mesmo cacho.

Em condições de tempo suficientemente úmido, as bagas da nificadas não tardam a ser afetadas por agentes secundários diversos, tais como a podridão cinzenta que contamina os grãós sadios, bem como passa a contribuir para a disseminação de en fermidades que acidificam o vinho. o dano acumulado é signif cativo, tendo em vista o elevado potencial de reprodução dā espécie. Vários métodos de controle foram testados na França e outros países europeus (ROECHRIK \& SCHMID, 1979 e ROECHRIK, 1981) com resultados satisfatórios. Esta praga deve ser diferenciada da Eudêmia americana Polychrosis viteana Clem., lagarta da baga da uva, que desenvolve duas gerações por ano.

Os inspetores fitossanitários devem ficar atentos às uvas em cacho provenientes de países europeus.

otiorrynchus sulcatus Fabricius (sinônimo de Brachyrhinus sulcatus) e outros otiorrynchus (Coleoptera, Curculionidae), gorgulho da videira.

Esta praga é de grande importāncia no hemisfério norte, incluindo os Estados Unidos, onde foi recentemente introduzida da Europa (GALET, 1982; BAYER, 1967 e DUGAN, 1977). Seu da no é causado pelos adultos que se alimentam nas gemas e folhas tenras. Têm grande capacidade reprodutiva e são polífagos. Sua introdução pode ser feita junto com mudas de vıdeıra ou, mais provavelmente, em plantas ornamentais, na forma de ovos ou larvas no solo. Os adultos, por serem ativos e facilmente visiveis a olho nu, podem ser imediatamente descobertos. O inseto é anotado nesta lista dado aos danos econômicos que causam em países europeus.

Tetranychus pizosus e T. telarius (Tetranychidae, Acarina), ácaro vermelho ou aranha vermelha da videira.

De acordo com informações de Flechtmann* (1985) (comunicação pessoal), T. pilosus Canestrini \& Fonzago é sinônimo de

* Carlos Flechtmann, Divisão de Zoologia/ESALQ Piracicaba, São Paulo. 
Panonychus ulmi Koch, 1836, chamado também de "Ácaro vermelho europeu", praga importante da macieira em Santa Catarina. Embora assinalado no Brasil há vārios anos, não se conhece re gistro de ocorrência em videiras no sul do país. Deve-se manter um sistema de vigilância fitossanitária para impedir que a espécie se multiplique e se difunda dentro dos parreirais. pelo seu tamanho quase microscópico, estes ácaros podem passar despercebidos a olho nu nas rotinas de vigilância fitossa nitária. Sugere-se, assim, que o material botānico proveniente das regiões onde ocorre deva ser sempre fumigado como brometo de metila ou com fosfina (GALET, 1982).

O ácaro T. telarius (Linnaeus), cujas fêmeas verdes são referidas por T. urticae Koch, 1836, e as fêmeas vermelhas conhecidas por $T$. cinnabarinus Boisduval, 1867, têm um outro si nônimo, T. vitis Boisduval (Flechtmann 1985, comunicação pessoal).

Outros ácaros, particularmente da família Eryophidae, de vem ser incorporados gradativamente na lista ora referida.

\section{Xiphinema index (Thorne \& Allen, 1950)}

E um nematóide de considerável importância para a viticultura por ser um vetor eficiente do vírus conhecido como "Fanleaf" (USA) e "Court noué" (França) e de suas raças "Yellow mosaic" e "Vein banding". Este vírus é um dos mais importantes da videira, ocorrendo em praticamente todas as áreas vití colas do mundo. Em geral, todas as cultivares, tanto de produ toras como de porta-enxertos, são suscetiveis. O vírus causā a progressiva degeneração da planta, queda da produção e da qualidade da uva, além de reduzir a vida útil do vinhedo e sua resistência às condiões adversas de clima. Os sintomas externos da virose podem ocorrer em todos os órgãos da planta, sen do os principais a deformação das folhas, o achatamento, entrenós curtos e bifurcação dos ramos, a diminuição do número e tamanho das bagas e a presença de bagoinhas nos cachos (fal ta de desenvolvimento das bagas) (GALET, 1977; BOVEY et al., 1980; e MARTELLI \& PROTA, 1985).

SEGUNDO GALET (1977, 1982), Xiphinema index é um nematói de relativamente grande, atingindo entre $1 \mathrm{~mm}$ para larvas e $3 \mathrm{~mm}$ para fêmea adulta. os machos são muito raros e não participam da multiplicação, que é partenogenética. Sua reprodução varia muito com as condições climáticas, podendo a fêmea produzir de 1 a 100 ovos. A larva passa por 4 mudas para atingir o estado adulto, o que pode levar diversos meses dependendo do lo cal e época do ano. Y. index é dotado de um longo estilete, mō tivo pelo qual é conhecido como "dagger-nematodes". É um nemā tóide ectoparasita que ataca, de preferência, as radicelas, poo dendo, ocasionalmente, provocar deformação no ápice destas è até nodosidade quando a população é elevada. Além da videira, 
X. index multiplica-se também sobre a figueira, o jasmim, o á lamo e em algumas outras espécies vegetais. Poucas horas após ter se alimentado de plantas doentes, o nematóide adquire o virus, podendo permanecer virulífero na ausência de hospedeiros por um período de até 120 dias (GALET, 1977).

A disseminação dos nematóides dentro do vinhedo pode ser feita por meio de tratos culturais, como aração e capinas, on de os nematóides são transportados no solo aderidos aos implē mentos agrícolas. Também podem ser propagados através da águā de irrigação ou enxurradas. Já entre regiões ou mesmo de um país para outro, os nematóides são introduzidos através do sis tema radicular das mudas importadas.

Além de $x$. index, outras espécies de menor importância são vetoras de vírus que afetam a videira, como $X$. italiae (Meyl, 1953), que igualmente transmite o virus do "Fanleaf" ou "Court noué", X. diversicaudatum (Micoletzki,1972), que trans mite o "Arabis mosaic virus" e X. americanum Cobb, que é vetor do "Peach rosset mosaic virus". Também o nematóide Longido rus attenuatus Hopper é vetor do "tomato black ring virus"para a videira (BOVEY et al., 1980).

X. index, principal vetor de vírus da videira, é bastante comum na maior parte dos vinhedos mediterrâneos. Na Europa, já foi constatado na Alemanha, Hungria, Suíça, Grécia e Itália; na África, foi encontrado na Tunísia e Algéria; na Asia, no Iran e Turquia; e na América nos Estados Unidos, Argentina e Chile (GALET, 1982; e GONZALES, 1970).

No Brasil, nas regiões vitícolas pouco se conhece a respeito da ocorrência de nematóides vetores de vỉrus (FERRAZ, 1977). Em levantamentos conduzidos até o momento não se verificou nenhuma das espécies mencionadas como vetores. Tem-se constatado nematóides do gēnero Xiphinema, principalmente X. brasiliensis; porém, não se tem informações se esta espécie é vetora de vírus.

O controle de nematóides vetores somente é eficiente pela fumigação do solo antes do plantio. A aplicação de produtos sistêmicos em plena vegetação não apresenta bons resultados, pois o nematóide somente pode ser atingido pelo produto se sugar a seiva da planta e, consequementemente, no momento em que se dá a penetração do estilete nas células ocorre a inoculação do vírus antes da morte do nematóide.

O produto fumigante mais empregado no preparo de solo pa ra viveiro de mudas de videira é o Dicloropropeno-Dicloropropā no (DD) na dosagem de $1000 \mathrm{l} / \mathrm{ha}$. Outros produtos também são uti் lizados, como o Brometo de metila e o 1,3 Dicloropropano. Estes produtos devem ser liberados a uma profundidade aproximada de $30 \mathrm{~cm}$ quando o solo estiver com uma temperatura entre 8 e $20^{\circ} \mathrm{C}$ e não muito seco. Este tipo de tratamento é muito caro, sendo 
economicamente viável somente em pequenas áreas como em vivei ros de produção de mudas.

Em mudas enraizadas, pode-se fazer antes do plantio a po da do sistema radicular, deixando-se com 10-15cm de comprimen to e posteriormente a imersão das raízes em água quente a $50 \bar{C}$ durante 10 minutos. Para maior eficiência do tratamento, deve se adicionar formalina comercial (40\%) na proporção de $1 \ell / 400 l$ de água.

\section{LITERATURA CITADA}

BAYER. Compêndio Fitossanitärio. Leverkusen, Alemanha, $2 \mathrm{v} .$, pág. irreg.

BOVEY, R.; GARTEL, W.; HEWITT, W.B.; MARTELLI, G.; VUITENNEZ, A. Malades à virus et affections similaires de la vigne. Pa ris, Payot Lausanne, 1980, 180p.

BRASIL. MINISTERIO DA AGRICULTURA. SECRETARIA NACIONAL DE DEFESA AGROPECUÁRIA. SECRETARIA DE DEFESA SANITÁRIA VEGETAL. DIVISÃO DE PROFILAXIA E COMBATE ÀS PRAGAS E DOENÇAS DOS VE GETAIS. 1983. Lista de pragas e doencas de importância qua rentenäria para o Brasil. Brasilia, Serviço Público Federal, 1983. 37p. (Informativo Técnico).

BRASIL. MINISTERIO DA AGRICULTURA. SECRETARIA NACIONAL DE DEFESA AGROPECUÁRIA. SECRETARIA DE DEFESA SANITÁRIA VEGETAL. DIVISÃO DE PROFILAXIA E COMBATE ÀS PRAGAS E DOENÇAS. 1979. Legislagão fitossanitaria brasileira. Brasilia, Serviço Pü blico Federal, 1979. 151p.

BRASIL. MINISTERIO DA AGRICULTURA. SECRETARIA NACIONAL DE DEFESA AGROPECUÁRIA. SECRETARIA DE DEFESA SANITÁRIA VEGETAL. 1980. Regulamento de defesa sanitária vegetal (Aprovado pe 1o Decreto no 24.114, de 12 de abril de 1934 e publicado no "Diário oficial" de 4 de maio do mesmo ano). 4. ed. Bra sília, Serviço Püblico Federal, 1980. 34p.

CAUDWELL, A.; LARRUE, J.; MOUTOUS, G.; FOS, A.; BRUN P. La transmission par des cicadelles de la jaunisse du vignoble corse. Identification de cette maladie avec la Flavescence dorée I. - Les essais réalizés hors de la Corse. Ann. Zool. Ecol. Anim. 10(4):613-625, 1978.

CAUDWELL, A. ; LARRUE, J.; KUSZALA, C.; FLEURY, A. La flavescen cence dorée de la vigne en France. Phytoma - Defense des cultures, Fevrier 1981. pp.16-19.

DUGAN, T.F. Ohio researchers conduct black vine weevil studies, American Nurseryman 145(9):108-113, 1977. 
FERRAZ, L.C.C.B. Estudo sistemático das espécies brasizeiras do gênero Xiphinema Cobb. 1913 (Nemata, Longidoridae). Piracicaba, ESALQ. 1977. 75p. (Tese de Mestrado).

GALET, P. Les maladies et les parasites de la vigne. Montpellier, Imprimerie du Paysan du Midi, 1977. v.1., 871p.

GALET, P. Les maladies et les parasites de la vigne. Montpellier, Imprimerie du Paysan du Midi, 1982. v.2., p.883 - 1876.

GALLO, D.; NAKANO, O.; WIENDEL, F.M.; SILVEIRA NETO, S.; CARVALHO. R.P.L. Manual de entomologia agricola. São Paulo, Ed. Agron. Ceres, 1978. 531p.

GALLOTTI, B.J. Contribuicão para o estudo de biologia e para - controle quimico de Eurhizoccus brasiliensis (Hempel, 1922). Curitiba, UFPR, 1976. 63p. (Tese de Mestrado).

GoBbAto, C. Manual do viti-vinicultor brasileiro. 4 a ed. Porto Alegre, Globo, 1940. v.1.422p.

GONZALES, R.H. Nuevas especies de nematodos que atacan la vid en Chile. Agricultura tec. 30(1):31-36, 1970.

GONZALES, R.H.; KIDO, H.; MARIN, A.; HUGHES, P. Biologia e en saios preliminares em controle de Margarodes (Margarodes vitis, Phillips). Agricultura tec. 29(3):93-122, 1969.

MARIN-LEON, M.A. Investigaciones biologicas sobre el margarodes de la vid., Margarodes vitis (Phil.) (Hom. Coccoidea). Santiago, Universidade de Chile, 1968. 140p. (Teses Eng?. Agrônomo).

MARTELLI, G.P. \& PROTA, V. Virosi della vite. L'Italia Agrico Za. $122: 201-228,1985$.

MoUTOUS, G. \& FOS, A. La lutte contre la flavescence dorée et les cicadelles de la vigne. Rev. Zool. Agric. Pathol. vég. $7: 55-69,1972$.

MOUTOUS, G. \& FOS, A. Influence des niveaux de populations de cicadelles de la vigne (Empoasca flavescens $F a \bar{b}$.) sur le symptome de la "grillure" des feuilles. Ann. Zool. Ecol. Anim. 5(2):173-185, 1973.

MOUTOUS, G.; FOS, A.; BESSON, J.; JOLY, E. ; BILAND, P. Resultats d'essais de ovicides contre Scaphoideus littoralis Ball. cicadelle victrice de la Flavescence dorée. Rev. Zool. Agric. Pathol. veg. 76:37-49, 1977.

PANIZZI, A.R. \& NOAL, A.C. Eurhizococcus brasiliensis (Hempel, 1922), Disseminação no município de Passo Fundo. Hospedeiro e Dados Biológicos. Passo Fundo, Universidade de Passo Fundo, IPEPLAN, 1971. 34p.

ROECHRICH, R. Travaux du sous-groupe "Tordeuses de la grappe". Bolz. Zool. Agr. Bachicolt., Ser. II 16:7-34, 1981. Trabalho apresentado na IV Réunion Plénière, Gargnano, Italie, mars 1981. 
ROECHRICH, R. \& SCHMID, A. Lutte integrēe en viticulture. Tor deuses de la grappe: Evaluation du risque, determination des periodes d'intervention et recherche des methodes de lutte biologique. In: SYMPOSIUM INTERNATIONAL OILB/SROP SUR LA LUTTE INTEGREEE EN AGRICULTURE ET EN FORET. PROCEETINGS. Wien (8) $12: 245-254,1979$.

SILVA, A.G.A.; GONÇALVES, C.R.; GALVÃO, D.M.; GONÇALVES, A.J.L; GOMES, J.; SILVA, M.N.; SIMONI, L. Quarto catälogo dos insetos que vivem nas plantas do Brasiz. Rio de Janeiro, Ministério da Agricultura. 1967. Part. 1; v.1.,p.1-422; v.2., p.423-906; 1968. Part. 2; v.1., 622p., v.2., 265p.

WILLE, J. Margarodes brasiziensis. Egatea 1(2):83-85, 1922.

WILLE, J. Margarodes brasiliensis. Fazenda Moderna $g(1): 1,1924$. 